\title{
SOME ASPECTS OF THE EFFECT OF CYPROTERONE ACETATE ON LEVELS OF OTHER STEROID HORMONES IN MAN
}

\author{
JANET BROTHERTON* AND G. BARNARD $\uparrow$ \\ Schering Chemicals Ltd, Burgess Hill, Sussex
}

(Received 19th March 1973)

\begin{abstract}
Summary. The mean plasma testosterone level after 6 to 17 months in seven adult males receiving $100 \mathrm{mg}$ oral cyproterone acetate daily, was $267 \pm 125 \mathrm{ng} / 100 \mathrm{ml}( \pm$ S.D.) with a range of 99 to 518 . This represents a reduction of only $65 \%$ from the normal controls. Plasma androstenedione levels showed a mean of $125 \pm 93 \mathrm{ng} / 100 \mathrm{ml}( \pm$ S.D.) with a range of 52 to 162 which is within the normal range. The same dose of cyproterone acetate given to two female volunteers from Day 5 of the menstrual cycle for 10 days caused a reduction in urinary total oestrogen and pregnanediol to levels inconsistent with ovulation. With the addition of $0.05 \mathrm{mg}$ ethinyloestradiol from Day 5 for 21 days, as in the 'Reverse Sequential Regime', ovulation appeared to be inhibited in all the ten cycles studied. There were regular 'withdrawal bleedings'. When the oestrogen was continued alone, ovulation returned in both women and after the cessation of all steroid treatment their normal pattern of hormone excretion continued. These results are discussed in relation to the possible mechanism of action of cyproterone acetate.
\end{abstract}

\section{INTRODUCTION}

The feedback inhibition of the hypothalamo-pituitary axis by progestagens has been well documented both in males (Brotherton, 1972) and in females (Goldzieher, Kleber, Moses \& Rathmacher, 1970). Their potency is weak compared with that of oestrogens or androgens. In very small doses (30 to $50 \mu \mathrm{g}$ ethinyloestradiol/day), oestrogens appear to inhibit FSH secretion more than LH secretion both in women (Yen \& Tsai, 1971) and men (Reiter \& Kulin, 1972). The general effect of the pregnane-type progestagens is to suppress LH rather than FSH. This has been shown for medroxyprogesterone acetate (MPA) in both males (Gordon and his co-authors, 1970) and females, in whom FSH remained essentially at normal levels for the luteal phase with doses of $150 \mathrm{mg}$ MPA intramuscularly every 3 months (Goldzieher et al., 1970). Cyproterone acetate is a powerful progestagen, structurally related to progesterone, but is also the most powerful antiandrogen known (Brotherton,

* Present address: Department of Chemotherapy, Schering AG, 1 Berlin 65, Müllerstr. 170-172, Germany.

$\uparrow$ Present address: Department of Obstetrics and Gynaecology, King's College Hospital Medical School, Denmark Hill, London. 
1973). Its feedback potency at a dose of $2 \times 50 \mathrm{mg}$ orally/day in adult males has been shown to be weak (Brotherton, 1974) so that there was no detectable difference in LH and FSH levels. This was thought to be due to its antiandrogenic properties, which allow an increase in gonadotrophin secretion due to prevention of central inhibition by androgen, cancelling out the weak inhibition due to the progestagenic properties. It is well known that, for women, oestrogen or progestagen alone does not consistently inhibit ovulation but when the same amounts of the two compounds are mixed, as in the combined type of oral contraceptive, there is a complete inhibition of the mid-cycle ovulatory peaks of LH and FSH.

The inhibition of LH and/or FSH secretion by oestrogen and/or progestagen is reflected in the steroid hormone secretion of the target organs. The pregnanetype progestagens given alone in large doses inhibit testosterone secretion only to about a fifth of normal in adult males (Sundsfjord, Aakvaag \& Norman, 1971 ; Kirschner \& Schneider, 1972). In females given small doses continuously, plasma progesterone or urinary pregnanediol levels are little affected. Mixed preparations containing an oestrogen and a progestagen cause ovarian quiescence with reduction of natural oestrogen and progestagen secretion to basal levels. It is clear that cyproterone acetate causes a significant reduction in the plasma testosterone levels in males (Schoonees, Schalch \& Murphy, 1971; Sorcini, Sciarra, di Silverio \& Fraioli, 1971). This may be as much as $50 \%$ in the first 5 days of therapy but the doses used were in the higher range for the treatment of prostatic carcinoma. We now report some plasma testosterone levels in males treated with the lower dose of cyproterone acetate used in the treatment of hypersexuality together with some urinary oestrogen and pregnanediol levels in females treated with the same dose, with and without the addition of oestrogen.

\section{METHODS}

\section{Volunteers}

The males received $50 \mathrm{mg}$ cyproterone acetate orally twice a day for the treatment of hypersexuality and have been described previously (Brotherton, 1974).

In addition, this study involved two female volunteers: M.L. was aged 37, married with two children and menstruated regularly; A.B. was 47 , single and menstruated occasionally. Both women had been extensively investigated previously and had undergone a variety of unsuccessful therapeutic regimens for their hirsutism, for which no organic cause had been found (Ismail, Davidson, Kirkham \& Loraine, 1969; Ismail, Loraine, Cullen \& Irvine, 1970). Each volunteer collected 24-hr urine specimens for a control period, one cycle treated with $50 \mathrm{mg}$ cyproterone acetate twice a day from Day 5 of the cycle for 10 days and then four cycles treated with the 'Reverse Sequential Regime' (Hammerstein \& Cupceancu, 1969). This consisted of $100 \mathrm{mg}$ cyproterone acetate plus $0.05 \mathrm{mg}$ ethinyloestradiol/day from Day 5 of the cycle for 10 days and then the ethinyloestradiol alone for a further 11 days, so making a normal contraceptive regimen of 21 days with gaps of 7 days between 
treatments. The cyproterone acetate was given for only 10 days as studies have shown that its plasma half-life is exceptionally long (Kolb \& Schulze, 1969). The 'Reverse Sequential Regime' has been shown to be an effective treatment for idiopathic hirsutism in a large number of women, although treatment for about 6 to 9 months is usually necessary before the improvement becomes marked (Hammerstein \& Cupceancu, 1969; Göbel, Cyran, Frick, Schindler \& Schwarz, 1972). At the end of eight cycles of this therapy, M.L. took the ethinyloestradiol alone for 3 cycles and collected urine samples up to the end of another control cycle, making fourteen cycles in all. At the end of fourteen cycles of therapy, A.B. took ethinyloestradiol alone for one cycle and continued collecting urine for a further 3 months.

\section{Oestrogen estimation}

Total urinary oestrogens were determined by the 'short Brown' method (Brown, MacLeod, MacNaughton, Smith \& Smyth, 1968; Brown, MacNaughton, Smith \& Smyth, 1968), with a number of minor modifications described below. All chemicals were of Analar grade or better. Distilled rather than deionized water was used.

Hydrolysis. For non-pregnancy urine with an expected total oestrogen content below $40 \mu \mathrm{g} / 24 \mathrm{hr}$, two $1-\mathrm{ml}$ aliquots of the thawed and thoroughly mixed samples were processed in duplicate. For each batch of twelve unknown urine samples, single samples of the same 24-hr urine specimen from each of the two patients were processed to act as an internal control, a single sample of postmenopausal urine and extra samples of unknown urines to which standard oestriol was added later. Each urine sample was made up to $1 \mathrm{ml}$ with water if necessary, $6.2 \mathrm{ml}$ of an acid mixture (prepared by adding $\mathrm{HCl}$ to water in the proportion of $12: 50 \mathrm{v} / \mathrm{v}$ ) were added, a glass stopper was placed lightly on the top of the tube and the mixture was hydrolysed in a boiling water bath for $30 \mathrm{~min}$. After rapid cooling to room temperature, $100 \mu \mathrm{l}$ of a standard solution of oestriol (Steraloids Ltd), prepared as $1 \mu \mathrm{g}$ oestriol $/ \mathrm{ml}$ ethanol, was added to and mixed with the extra urine hydrolysates.

Extraction. The volume of each compartment A of the vessels of the special oestrogen extraction machine (Arnold Horwell Ltd, 2 The Grangeway, Kilburn High Road, London, N.W.6) was found to vary between 5.4 and $5.7 \mathrm{ml}$ (nominally $6.0 \mathrm{ml}$ ) and marked on each vessel. The contents of each urine hydrolysis tube were tipped into a vessel, and were augmented by the washings resulting from the addition of $6 \mathrm{ml}$ diethyl ether to the hydrolysis tube and vortex mixing. About $1 \mathrm{~g} \mathrm{NaCl}$ was added and dissolved by rocking the vessels mechanically. Extraction of free steroids into the ether layer was continued for about $3 \mathrm{~min}$, ending with the vessels standing at about $45^{\circ}$ from the vertical. After settling of the phases, residual bubbles of the ether phase were expelled upwards from the aqueous phase by the use of a rubber teat temporarily attached to the end of the S-shaped capillary tube at the bottom of each vessel. The vessels were then adjusted to the vertical position and the lower aqueous phase drained away until the meniscus representing the bottom of the ether phase was in the first downward part of the capillary. The vessels were adjusted to the horizontal position, $2 \mathrm{ml}$ carbonate solution $\mathrm{pH} 10.5$ (Brown, MacLeod 
et al., 1968) were added, automatic extraction was carried out for 3 min and the lower aqueous phase containing the acidic steroids was discarded as before. To each ether phase were added $6 \mathrm{ml}$ petroleum spirit, B.P. 40 to $60^{\circ} \mathrm{C}$, and the exact quantity of $\mathrm{N}-\mathrm{NaOH}$ indicated for that particular vessel. Automatic extraction of the phenolic steroids into the lower aqueous layer was carried out for $3 \mathrm{~min}$, ending with the vessels adjusted to the vertical position except that the opposite end was now upwards. The upper solvent layer containing the neutral steroids was run off and discarded, so leaving the exact volume of aqueous layer just filling compartment A. About $0.8 \mathrm{~g} \mathrm{NaHCO}$, which was dissolved by automatic rocking, and $6 \mathrm{ml}$ diethyl ether were added to compartment A. The phenolic steroids were then re-extracted into the ether phase by automatic rocking for $3 \mathrm{~min}$ and the lower aqueous phase was run off as

Table 1. Effect of different methods of applying standard oestriol to test urine samples from two female volunteer subjects

\begin{tabular}{|c|c|c|c|}
\hline \multirow{2}{*}{ Method } & \multirow{2}{*}{$n$} & \multicolumn{2}{|c|}{$\begin{array}{l}\text { Fluorescence reading at } \\
0.001 \text { sensitivity }\end{array}$} \\
\hline & & Mean & Range \\
\hline $\begin{array}{l}\text { Evaporated alone } \\
\text { Evaporated with } 6 \mathrm{ml} \text { ether } \\
\text { Evaporated with hydrolysed urine }\end{array}$ & $\begin{array}{r}20 \\
4 \\
17\end{array}$ & $\begin{array}{r}681 \\
231 \\
1288\end{array}$ & $\begin{array}{r}420 \text { to } 1020 \\
126 \text { to } 340 \\
1003 \text { to } 1671\end{array}$ \\
\hline
\end{tabular}

before. The solution in ether was then tipped into a collecting tube together with a small amount of aqueous phase, from which it was separated by pouring into another tube. Stoppered ether extracts could be stored at $4^{\circ} \mathrm{C}$ for at least 1 week at this stage.

Kober-Ittrich reaction. Ittrich reagent $(0.75 \mathrm{ml})$ was placed into ice-cold fluorimeter tubes. This was prepared by dissolving $2 \mathrm{~g} p$-nitrophenol (KochLight Ltd), recrystallized from benzene, in $1 \mathrm{ml}$ ethanol with warming, adding $100 \mathrm{ml}$ sym-tetrachloroethane and storing at $4^{\circ} \mathrm{C}$. An anti-bumping granule $(\mathrm{BDH})$ was added to each ether extract of phenolic steroids. Evaporation to complete dryness in a water bath at $60^{\circ} \mathrm{C}$ was achieved in about $10 \mathrm{~min}$ and $1 \mathrm{ml}$ Kober reagent was added. This was prepared by dissolving $2 \mathrm{~g}$ quinol (BDH) in $100 \mathrm{ml} 66 \% \mathrm{v} / \mathrm{v}$ sulphuric acid in water to form a colourless solution that was stored in the dark. The addition of an extra $1 \mathrm{mg}$ powdered quinol to the reaction mixture at this stage was found to be unnecessary. It is essential that quinol and carbonate do not come into contact in the presence of water, otherwise there is a serious interference with the Kober reaction. The tubes were lightly stoppered, the Kober reaction was carried out at $120^{\circ} \mathrm{C}$ in an oil bath for exactly $10 \mathrm{~min}$, the tubes were cooled rapidly to $4^{\circ} \mathrm{C}$ and $1.5 \mathrm{ml}$ water at $4^{\circ} \mathrm{C}$ were added with further cooling. The ice-cold diluted Kober reagent was poured into the ice-cold fluorimeter tube containing the Ittrich reagent. The fluorimeter tubes were stoppered, the fluorescence extracted in the lower layer by shaking long and vigorously, and the tubes were centrifuged at $2000 \mathrm{rev} / \mathrm{min}$ for $3 \mathrm{~min}$ at $-5^{\circ} \mathrm{C}$. 
Fluorimetry. The fluorimeter tubes were allowed to stand briefly at room temperature until misting of their lower optical sections ceased; they were then wiped. Fluorescence due to oestrogen was measured in an Aminco-Bowman 4-8202 Spectrophoto-fluorimeter equipped with the mercury-xenon lamp, at maximum sensitivity with an excitation wavelength of $546 \mathrm{~nm}$ and an emission wavelength of $565 \mathrm{~nm}$, and background fluorescence was measured at an excitation wavelength of $490 \mathrm{~nm}$ and an emission wavelength of $520 \mathrm{~nm}$. A correction factor, $\mathrm{K}$, falling between 1.0 and 1.6 , was calculated from the postmenopausal urine as the ratio of the fluorescence due to 'oestrogen' and the background fluorescence. This factor was applied to the background fluorescence of the unknown samples. The oestrogen content of each urine was calculated from the fluorescence produced in proportion to that of the same urine with added oestriol standard, assuming linearity with concentration (Brown, MacNaughton, Smith \& Smyth, 1968). This method of calculation corrected

Table 2. Effect on the total oestrogen level in urine samples from a female volunteer subject following the addition of cyproterone acetate

\begin{tabular}{l|ccccc}
\hline & \multicolumn{5}{|c}{ Cyproterone acetate added $(\mu \mathrm{g})$} \\
& 0 & 1 & 5 & 20 & 40 \\
\cline { 2 - 6 } Total oestrogen $(\mu \mathrm{g} / 24 \mathrm{hr})$ & $9 \cdot 4$ & $12 \cdot 2$ & $9 \cdot 4$ & $10 \cdot 1$ & $10 \cdot 8$ \\
\hline
\end{tabular}

for partial recovery of phenolic steroids through all stages after the hydrolysis.

Incorporation of standards. The method described above whereby standard oestriol was added to the urine hydrolysates was found to be more accurate and reproducible than other commonly used alternatives. Table 1 shows that the fluorescence due to oestrogen was much reduced if the oestriol standard was evaporated in an empty tube before the application of Kober-Ittrich reagent. Even lower fluorescence readings were found if the standard oestriol was first evaporated with $6 \mathrm{ml}$ diethyl ether at $60^{\circ} \mathrm{C}$, so mimicking the condition of the urine extracts. Duplicate values and reproducibility of results were all within the accepted limits of the method (Brown, MacLeod et al., 1968).

Interference by cyproterone acetate. Cyproterone acetate in quantities of $1,5,10$, 20 and $40 \mu \mathrm{g}$ was added to a standard urine and processed in the usual way. Table 2 shows that there was no significant interference in the amount of total oestrogens estimated, even after the addition of $40 \mu \mathrm{g}$ cyproterone acetate.

\section{Pregnanediol estimation}

Pregnanediol levels were determined by a gas-liquid chromatographic method based on work by Cox (1963) and Metcalf (1968). Filtered urine was hydrolysed with hydrochloric acid, an internal standard (progesterone) was added and the mixture was extracted with dichloromethane. The extract was washed with alkali and water and evaporated to dryness at $45^{\circ} \mathrm{C}$. The residue was dissolved in acetone and amounts equivalent to 40 to $60 \mu \mathrm{l}$ urine were chromatographed on glass OV 17 columns (1\% methyl silicone:phenyl 
silicone $1: 1$ on Diatomite CQ, 100 to 120 mesh, Pye-Unicam, Cambridge) using argon as the carrier gas and a temperature of $255^{\circ} \mathrm{C}(\mathrm{H}$. Braunsberg, personal communication). Recovery of free pregnanediol added after hydrolysis was $97.9 \% \pm$ S.D. $9 \cdot 1$ (range 83.5 to $113, n=5$ ). Recovery of free pregnanediol added before hydrolysis was $92.3 \% \pm$ S.D. 10.9 (range $72 \cdot 1$ to $103, n=13$ ). Recovery of pregnanediol glucuronide added before hydrolysis was $92.9 \%$ \pm S.D. 6.5 (range $81 \cdot 5$ to $104, n=11$ ).

\section{Testosterone and $\Delta^{4}$-androstenedione}

These hormones were measured in the same plasma sample after extraction with diethyl ether and chromatography on commercially prepared (Kodak Ltd) silica gel thin-layer plates (W. R. Butt \& B. T. Rudd, personal communication). For estimation of recoveries, $6000 \mathrm{~d} / \mathrm{min}$ of $\left[{ }^{3} \mathrm{H}\right]$ testosterone and $10,000 \mathrm{~d} / \mathrm{min}\left[{ }^{3} \mathrm{H}\right]$ androstenedione were evaporated to dryness in the tube before the addition of $3 \mathrm{ml}$ plasma or $3 \mathrm{ml}$ water for the blank. This was followed by the addition of $0.3 \mathrm{ml} \mathrm{N}-\mathrm{NaOH}$ and extraction was carried out with $15 \mathrm{ml}$ diethyl ether. After washing and evaporation to dryness, the extract was loaded onto the plates in methanol and run in toluene:methylal: methanol, $85 \cdot 5: 10: 1.5 \mathrm{v} / \mathrm{v}$ for $90 \mathrm{~min}$, followed by a toluene:methanol, 95:5 $\mathrm{v} / \mathrm{v}$ for $60 \mathrm{~min}$. Strips were cut to separate the testosterone and androstenedione with the aid of ${ }^{14} \mathrm{C}$-markers and the steroids were extracted with methanol.

Each steroid was estimated by radioimmunoassay, utilizing an antiserum raised in sheep against a 3-oxime-bovine serum albumin conjugate prepared by the Ehrlanger mixed anhydride method. The antiserum for testosterone had a cross reactivity of $21.0 \%$ for $\Delta^{4}$-androstenedione and $19.2 \%$ for $\Delta^{4}$ androstene-3 $\beta, 17 \beta$-diol and was active at $1: 200,000$ dilution. The antiserum for androstenedione had significant cross reactivity with several steroids and gave a dose response curve at $1: 25,000$ dilution. Cross-reactivity in the actual assays was not significant due to the prior extraction and chromatographic separation of the steroids.

\section{RESULTS}

Androgen levels in males

Table 3 shows plasma testosterone and androstenedione levels from the group of adult male hypersexuals described previously (Brotherton, 1974). The mean testosterone level was $267 \pm$ S.D. $125 \mathrm{ng} / 100 \mathrm{ml}$ with a range of 99 to 518. In all cases significant amounts of plasma testosterone remained even after prolonged treatment, the mean as a result of treatment being about $35 \%$ of normal untreated men. The mean androstenedione level was $125 \pm$ S.D $93 \mathrm{ng} / 100 \mathrm{ml}$ with a range of 52 to 162 .

\section{Oestrogen and pregnanediol levels in females}

Text-figures $1(\mathrm{a})$ and $1(\mathrm{~b})$ show the urinary total oestrogens and pregnanediol levels for M.L. This volunteer has been extensively studied previously (Ismail et al., 1970) and has always exhibited very high testosterone levels in the presence of normal menstruation. Her pretreatment control Cycle 1 exhibited the 
normal biphasic oestrogen pattern and luteal phase pregnanediol excretion characteristic of the normal ovulatory cycle. Pregnanediol levels quoted as 'undetectable at below $1 \mathrm{mg} / 24 \mathrm{hr}$ ' have been plotted at $0.5 \mathrm{mg} / 24 \mathrm{hr}$ to distinguish them from samples where pregnanediol estimations were not performed. During Cycle A, when cyproterone acetate was given alone, there was a reduced oestrogen secretion and some pregnanediol was detected, though during the five cycles treated with the 'Reverse Sequential Regime' there was slight oestrogen excretion during withdrawal bleedings and at the beginning of the combined regimen, but pregnanediol remained undetectable throughout. There were episodes of withdrawal bleeding at the end of each cycle as expected and in accordance with the usual pattern of events with a combined-type oral

Table 3. Plasma androgen levels in hypersexual males

\begin{tabular}{c|l|c|c}
\hline $\begin{array}{c}\text { Case } \\
\text { no. }\end{array}$ & $\begin{array}{c}\text { Pooled samples, } \\
\text { months of } \\
\text { treatment }\end{array}$ & $\begin{array}{c}\text { Testosterone } \\
(\mathrm{ng} / 100 \mathrm{ml})\end{array}$ & $\begin{array}{c}\text { Androstenedione } \\
(\mathrm{ng} / \mathrm{l} \text { (00 } \mathrm{ml})\end{array}$ \\
\hline B.1 & $12,13,14$ & 140 & 90 \\
B.2 & $15,16,17$ & 487 & 158 \\
B.3 & 11,12 & 238 & 142 \\
& 13,14 & 271 & 110 \\
B.5 & 6 & 161 & 52 \\
& $7,10,11$ & 223 & 111 \\
B.7 & 13,14 & 99 & 143 \\
B.8 & 11,12 & 290 & 103 \\
& $13,14,15$ & 256 & 148 \\
B.9 & 12 & 250 & 162 \\
& 13,14 & 518 & 155 \\
\hline
\end{tabular}

contraceptive. The first cycle of treatment with ethinyloestradiol was anovulatory but ovulation had returned by the third such cycle. At the end of all therapy, the volunteer menstruated and ovulated normally again.

Text-figures 2(a) and 2(b) show the urinary total oestrogens and pregnanediol levels for A.B. She did not menstruate normally before the start of the study, nor after it had finished. During the Control Period 1, oestrogen and pregnanediol levels were high and in a range consistent with ovulation; but they did not show the typical biphasic pattern over the correct time interval. During Cycle A, when cyproterone acetate was given alone, the oestrogen levels were much reduced and pregnanediol levels were undetectable. During the five cycles treated with the 'Reverse Sequential Regime', there was slight oestrogen excretion during withdrawal bleedings and at the beginning of the combined regimen similar to that which occurred with M.L. At the end of the first cycle of treatment with ethinyloestradiol, there was a large surge of oestrogen excretion which appeared to be biphasic and lasted for about 28 days. Subsequently, oestrogen levels remained low. 


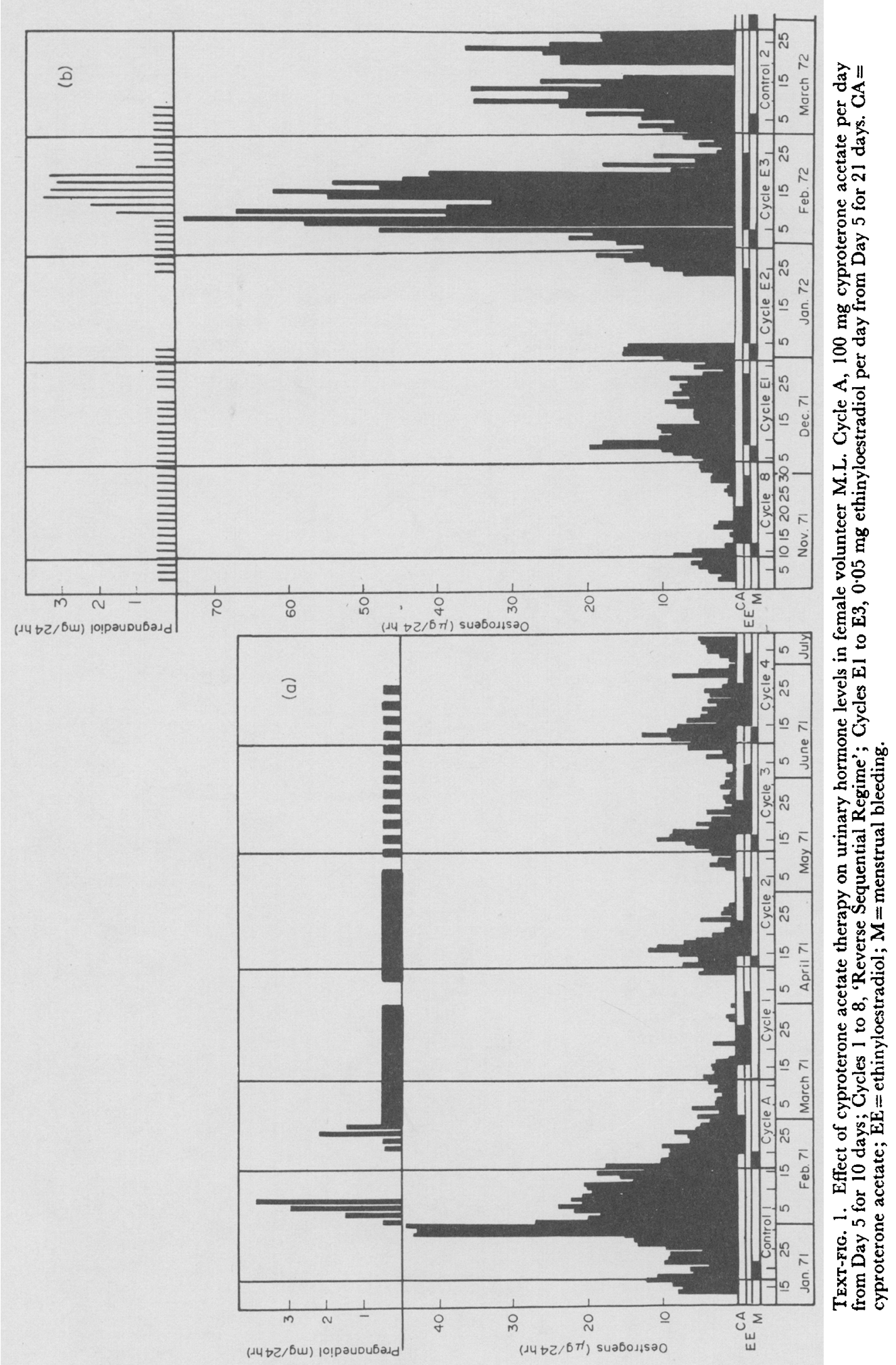




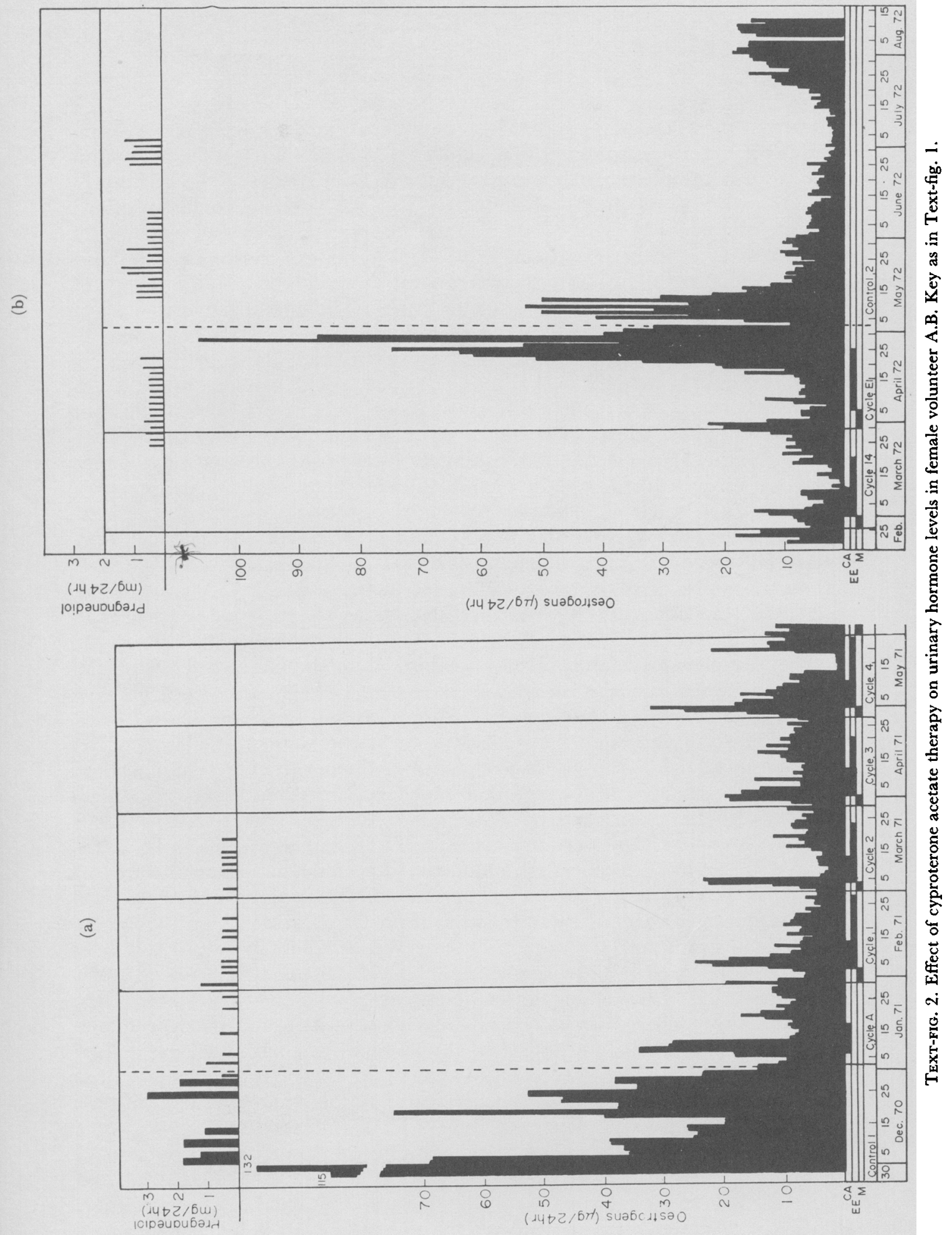




\section{DISCUSSION}

It is now well established that cyproterone acetate alone lowers plasma testosterone levels in males but that significant amounts of testosterone remain. The present results are well below the normal adult range of the laboratory of 435 to $1075 \mathrm{ng} / 100 \mathrm{ml}$ (W. R. Butt \& B. T. Rudd, personal communication) and the quoted mean of $709 \pm$ S.D. $143 \mathrm{ng} / 100 \mathrm{ml}$ with a range of 450 to 1100 (Dufau, Catt, Tsuruhara \& Ryan, 1972). This mean level during drug administration $(35 \%$ of the mean pretreatment level) is consistent with the reports of Schoonees et al. (1971) and Sorcini et al. (1971). The former found a mean of $100 \mathrm{ng}$ testosterone/100 ml after prolonged treatment with $100 \mathrm{mg}$ cyproterone acetate twice daily. It is remarkable that, with these residual plasma testosterone levels, the antiandrogenic action on the target organs in man should be so complete as to result in complete absence of an ejaculate after 6 weeks (Laschet \& Laschet, 1971). There is also a great improvement in female hirsutism after 6 to 9 months (Hammerstein \& Cupceancu, 1969). It has been postulated that there is a direct site of competitive inhibition with androgen.

When given alone in females, cyproterone acetate appeared to suppress ovulation in both cycles labelled A. The dose used here for a progestagen-only 'mini-pill' type of regimen is extremely high and this result is not surprising. At much smaller doses (e.g. $0.5 \mathrm{mg}$ chlormadinone acetate/day), the pregnanetype progestagens are effective contraceptive agents but ovulation is not usually inhibited (Diczfalusy, 1968).

The 'Reverse Sequential Regime' inhibited ovulation in all ten of the cycles examined and this again was expected. The fact that both patients produced the expected withdrawal bleedings was gratifying and has not been reported before. This indicates the satisfactory nature of the formulation of the regimen to allow for the prolonged pharmacokinetics of cyproterone acetate as shown, for example, by the detectable blood levels. The only significant difference between the regimen and that of a standard combined type of oral contraceptive then becomes the massive dose of the progestagen used, which also allows for a large antiandrogenic effect. It is difficult to account for the small surge of oestrogen excretion at the beginning of each cycle. The possibility that this was due to cyproterone acetate excreted in the urine was eliminated. After the single oral administration of $100 \mathrm{mg}$ cyproterone acetate, only $5 \%$ of the administered dose appeared in the urine over a period of 8 days (E. Gerhards, personal communication). Most of this elimination occurred in the first 2 days, being $2 \%$ of the administered dose on both these days, i.e. equivalent to $2 \mathrm{mg}$ cyproterone acetate/day. Assuming the volume of the $24-\mathrm{hr}$ urine to be $2000 \mathrm{ml}$, a $1-\mathrm{ml}$ sample would be expected to contain about $1 \mu \mathrm{g}$ cyproterone acetate. It has been shown that amounts considerably larger than this do not interfere with the oestrogen assay method. It is also believed that metabolites of cyproterone acetate are not the cause as it has been established that over $70 \%$ of urinary cyproterone acetate is excreted as conjugates of the unchanged molecule and most of the remaining conjugates are of a double acetate of cyproterone. The early oestrogen surge encountered in these two hirsute volunteers may be a 
manifestation of their disease in that the unsuppressed ovaries may restart the secretion of large amounts of oestrogen and androgen until they are suppressed again by the next sequential regimen.

That 'breakthrough' ovulation eventually occurred in both women while they were taking oestrogen alone is not surprising, as it is well known that this type of regimen does not consistently inhibit ovulation and is not effective for contraception (Carey \& Pinkerton, 1972a, b). It is also known that, after the withdrawal of such small doses of oestrogen, there is a surge of LH produced by 'positive feedback' (Yen \& Tsai, 1971) so that small doses of oestrogen can be used to induce ovulation.

It is to be noted that the volunteer M.L. resumed normal menstruation and ovulation immediately after all the hormonal manipulation over a period of 18 months. It is difficult to draw firm conclusions about the hormonal status of A.B., because of abnormal hormonal levels before and after the study and the absence of natural menstruation over the period studied. A large proportion, e.g. $85 \%$, of women with hirsutism and high androgen levels, do not menstruate or suffer from oligomenorrhoea (Cruickshank, Chapler \& Yannone, 1971). This effect is believed to be due to the high levels of circulating androgen and can be induced by androgen administration (Papanicolaou, Ripley \& Shorr, 1939).

The dynamics of androgen metabolism in women with hirsutism are now largely understood (Bardin \& Mahoudeau, 1970). Testosterone and several relatively non-androgenic precursors or prehormones are secreted into the blood by the adrenals and ovaries. A significant fraction of several precursors is converted to testosterone in the body. Androstenedione is the most important of these precursors and although in normal women only 3 to $4 \%$ is converted to testosterone, this accounts for about $50 \%$ of the plasma testosterone. The ovaries are believed to be the source of the excess androgen in the majority of cases (Kirschner \& Jacobs, 1971) and the long-term suppression of gonadotrophin secretion, and hence of the ovaries, with a high dose 'combined' type of oral contraceptive containing a powerful progestagen is commonly used for the treatment of idiopathic hirsutism. Many progestagens are also known to have a direct inhibitory effect on the ovaries (Diczfalusy, 1968; Mukherjee, Wright, Davidson \& Fotherby, 1972). It has been suggested that one of the modes of action of cyproterone acetate is to interfere with the biosynthesis of testosterone so producing more androstenedione in males (Sorcini et al., 1971). The androstenedione results presented here are not significantly different from the normal adult range of the laboratory of 58 to $289 \mathrm{ng} / 100 \mathrm{ml}$ (W. R. Butt \& B. T. Rudd, personal communication) and the quoted mean of $90 \mathrm{ng} / 100 \mathrm{ml}$ with a range of 30 to 170 for a GLC method (Kirschner \& Coffman, 1968). Considered together with the lowered plasma testosterone values, the results presented here are not inconsistent with this hypothesis. Similar findings have been reported elsewhere (Sciarra, Sorcini, di Silverio \& Gagliardi, 1971). In view of the similarity in structure between cyproterone acetate and progesterone or pregnenolone, it is considered that any interference in biosynthetic pathways is more likely to be at this level. There may be an alteration in the relative importance between the route from pregnenolone through progesterone to androstenedione and the route through dehydroepiandrosterone and 
androstenediol to testosterone, rather than a direct inhibition of the conversion of androstenedione to testosterone.

\section{ACKNOWLEDGMENTS}

We would like to thank Mr J. L. Newton, M.D., M.R.C.O.G., and Mr J. Tyler of the Department of Obstetrics and Gynaecology, King's College Hospital Medical School, for instruction and advice on the application of the method for oestrogen estimation and for the use of their laboratory facilities and the spectrofluorimeter. We also thank Dr H. Braunsberg, formerly of the M.R.C. Clinical Endocrinology Unit, Edinburgh and now of the Steroid Research Unit, Department of Chemical Pathology, St Mary's Hospital, London, for the pregnanediol estimations, Dr W. R. Butt of the Department of Clinical Endocrinology, The Birmingham and Midland Hospital for Women, and Dr B. T. Rudd of the Institute of Child Health, The Nuffield Building, Birmingham, for the testosterone and androstenedione estimations. We also thank Dr W. J. Irvine and Dr E. W. Barnes of the Department of Therapeutics, Royal Infirmary, Edinburgh, for the clinical management of and information about the two females studied and Dr T. S. Davies of Llanfrechfa Grange Hospital, Cwmbran, for the clinical management of the males studied.

\section{REFERENCES}

Bardin, C. W. \& Mahoudeau, J. A. (1970) Dynamics of androgen metabolism in women with hirsutism. Ann. clin. Res. 2, 251.

Brotherton, J. (1972) Bibliography (with review) on the clinical uses of anti-androgens. Biblphy Reprod. 20, 913.

Brotherton, J. (1973) Bibliography (with review) on animal experiments with anti-androgens. Biblphy Reprod. 21, 173.

BRotherton, J. (1974) Effect of oral cyproterone acetate on urinary and serum FSH and LH levels in adult males being treated for hypersexuality. 7. Reprod. Fert. 36, 177.

Brown, J. B., Macleod, S. C., MacNaughton, C., Smith, M. A. \& Smyth, B. (1968) A rapid method for estimating oestrogens in urine using a semi-automatic extractor. F. Endocr. 42, 5.

Brown, J. B., MacNaughton, C., Smith, M. A. \& Smyth, B. (1968) Further observations on the Kober colour and Ittrich fluorescence reactions in the measurement of oestriol, oestrone and oestradiol. F. Endocr. 40, 175.

Carey, H. M. \& Pinkerton, G. D. (1972a) The antifertility effectiveness of low doses of ethinyloestradiol. Med. F. Austr. i, 512.

Carey, H. M. \& Pinkerton, G. D. (1972b) Minimum ovulation inhibition levels of ethinyloestradiol. Med. F. Austr. i, 515.

Cox, R. I. (1963) Gas chromatography in the analysis of urinary pregnanadiol. f. Chromat. 12, 242.

Cruickshank, D. P., Chapler, F. K. \& Yannone, M. F. (1971) Differential adrenal and ovarian suppression. Diagnosis and treatment of androgenic disorders in women. Obstet. Gynec., N.r. $38,724$.

Diczfalusy, E. (1968) Mode of action of contraceptive drugs. Am. 7. Obstet. Gynec. 100, 136.

Dufau, M. L., CatT, K. J., Tsuruhara, T. \& Ryan, D. (1972) Radioimmunoassay of plasma testosterone. Clinica chim. Acta, 37, 109.

Göbel, P., Cyran, J., Frick, V., Schindler, A. E. \& Schwarz, M. (1972) Antiandrogen therapy for hirsutism. Acta endocr., Copenh. Suppl. 159, Abstract No. 100.

Goldzieher, J. W., Kleber, J. W., Moses, L. E. \& Rathmacher, R. P. (1970) A cross-sectional study of plasma FSH and LH levels in women using sequential, combination of injectable steroid contraceptives over long periods of time. Contraception, 2, 225.

Gordon, G. G., Southren, A. L., Tochimoto, S., Olivo, J., Altman, K., Rand, J. \& Lemburger, L. (1970) Effect of medroxyprogesterone acetate (Provera) on the metabolism and biological activity of testosterone. $\mathcal{F}$. clin. Endocr. Metab. 30, 449. 
Hammerstern, J. \& Cupceancu, B. (1969) The treatment of hirsutism with cyproterone acetate. Germ. med. Mon. 14, 599.

Ismail, A. A. A., Davidson, D. W., Kirkham, K. E. \& Loraine, J. A. (1969) Studies on sex hormone excretion in normal and hirsute women. Acta endocr., Copenh. 61, 283.

Ismail, A. A. A., Loraine, J. A., Cullen, D. R. \& IRvine, W. J. (1970) Studies of endocrine function in a hirsute woman. In: Reproductive Endocrinology, p. 122. Eds. W. J. Irvine and J. A. Loraine. Livingstone, Edinburgh and London.

Kirschner, M. A. \& Coffman, G. D. (1968) Measurement of plasma testosterone and $\Delta^{4}$-androstenedione using electron capture gas liquid chromatography. 7. clin. Endocr. Metab. 28, 1347.

KIRSCHNER, M. A. \& JACOBS, J. B. (1971) Combined ovarian and adrenal vein catheterization to determine the site(s) of androgen overproduction in hirsute women. 7. clin. Endocr. Metab. 33, 199.

Kirschner, M. A. \& Schneider, G. (1972) Suppression of the pituitary-Leydig cell axis and sebum production in normal men by medroxy-progesterone acetate. Acta endocr., Copenh. 69, 385.

Kol.B, K. H. \& Schulze, P. E. (1969) Pharmacokinetics of sexual steroids in man. In: Simposio Esteroides, Bogata, 1968, p. 16. Eds. F. R. Albrecht, J. R. Sanchez and H. Willomitzer. Saladruck, Berlin, Germany.

LAschet, U. \& LAschet, L. (1971) Psychopharmacotherapy of sex offenders with cyproterone acetate. Pharmakopsychiatrie Neuro-Pharmacologie, 4, 99.

Metcalf, M. G. (1968) Gas chromatography in the analysis of urinary pregnanediol. Analyt. Biochem. 25,510 .

MukherJeE, T. K., Wright, S. W., Davidson, N. J. H. \& Fotherby, K. (1972) Effect of norgestrel on corpus luteum function. 7. Obstet. Gynaec. Br. Commonw. 79, 175.

Papanicolaou, G. N., Ripley, H. S. \& Shorr, E. (1939) Suppressive action of testosterone propionate on menstruation and its effect on vaginal smears. Endocrinology, 24, 339.

Reiter, E. O. \& Kulin, H. E. (1972) Sexual maturation in the female. Normal development and precocious puberty. Pediat. Clins $\mathcal{N}$. Am. 19, 581.

Schoonees, R., Schalch, D. S. \& MUrPhy, G. P. (1971) The hormonal effects of anti-androgen (SH 714) treatment in man. Invest. Urol. 8, 635.

Sciarra, F., Sorcini, G., Di Silverio, F. \& Gagliardi, V. (1971) Testosterone and 4-androstenedione concentration in peripheral and spermatic venous blood of patients with prostatic adenocarcinoma. Effects of diethylstilbestrol and cyproterone acetate therapy. F. Steroid Biochem. 2, 313.

Sorcini, G., Sciarra, F., di Silverio, F. \& Fraioli, F. (1971) Further studies on plasma androgens and gonadotrophins after cyproterone acetate (SH 714). Folia endocr., Roma, 24, 196.

Sundsfjord, J. A., Aakvaag, A. \& Norman, N. (1971) Reduced plasma testosterone and LH in young men during progesterone administration. F. Reprod. Fert. 26, 263.

YEN, S. S. C. \& TsaI, C. C. (1971) The biphasic pattern in the feedback action of ethinyloestradiol on the release of pituitary FSH and LH. J. clin. Endocr. Metab. 33, 882. 